Original Research Article

\title{
Pharmacovigilance study in psychiatry out-patient department of a tertiary care teaching hospital
}

\author{
Nalini R.*
}

Department of Pharmacology, Tirunelveli Medical College, Tirunelveli, Tamilnadu, India

Received: 19 July 2017

Accepted: 22 August 2017

\section{*Correspondence to:}

Dr. Nalini R.,

Email: nalluprabha@gmail.com

Copyright: (C) the author(s), publisher and licensee Medip Academy. This is an openaccess article distributed under the terms of the Creative Commons Attribution NonCommercial License, which permits unrestricted noncommercial use, distribution, and reproduction in any medium, provided the original work is properly cited.

\begin{abstract}
Background: Adverse drug reactions are important in psychiatry practice like any other branch of medicine. Adverse drug reactions associated with psychotropic drugs causes either noncompliance or at times discontinuation of therapy. The objective of the study was to evaluate the incidence and nature of adverse drug reactions in psychiatry outpatient department and to assess the causality and severity of the documented adverse drug reactions.

Methods: Prospective observational study was done in the psychiatry outpatient department. All the patients were interviewed for basic details, history of medications and relevant history for adverse drug reactions. The causality, severity and modes of management assessment of the documented adverse drug reactions were done.
\end{abstract}

Results: 2,727 patients attended psychiatry outpatient department, of which 582 patients developed at least one adverse drug reaction. The incidence of adverse drug reaction observed to psychotropic drugs was $21.34 \%$. Majority of adverse drug reactions were seen with antidepressants 298 (10.93\%) followed by antipsychotics 187 (6.86\%), sedative hypnotics, anticonvulsants and antimanics. The most common adverse drug reactions were sedation $3.44 \%$, weight gain $3.04 \%$, and extrapyramidal symptoms $2.79 \%$. Reported adverse drug reactions were assessed for causality and maximum belonged to probable (15.6 9\%). The severity assessment of the reported adverse drug reactions revealed that most of the adverse drug reactions were mild $(16.83 \%)$ in nature and majority of patients were made to continue the same treatment.

Conclusions: Active monitoring of adverse drug reactions in psychiatry outpatient department can help in early detection and management of adverse drug reactions.

Keywords: Adverse drug reactions, Adverse drug monitoring, Pharmacovigilance, Psychotropic drugs, Psychiatry outpatient department

\section{INTRODUCTION}

Adverse drug reactions (ADRs) are important in psychiatry practice like any other branch of medicine. ${ }^{1}$ ADR monitoring in psychiatry unit play an important role in detecting the patients at high risk for developing ADRs and to understand the nature of ADRs in a local population which helps to alert the physicians about the possibility of such events thereby protecting the patients from avoidable harm. ${ }^{2,3}$
ADRs associated with psychotropic drugs causes either noncompliance or at times discontinuation of therapy. ${ }^{4}$ The incidence of serious and fatal ADRs in out- patient setting ranges from $5 \%$ to $35 \% .^{1}$ The study done by Solanke et al, reported that the overall incidence rate of ADRs was found to be $5.01 \%$ in psychiatry outpatient department (OPD) of a tertiary referral centre in central India. $^{5}$

Psychotropic drugs are plentiful in number and their use is increasing day by day. These drugs are capable of causing 
number of adverse drug reactions some of which may be fatal. ${ }^{3}$ A majority of the adverse drug reactions occur often due to considerable variability in the pharmacodynamic and pharmacokinetic parameters, drug interactions, increased reactive drug metabolites levels and their impaired detoxification. ${ }^{6}$

ADR may occur due to single dose, prolonged administration of drug or combination therapy of two or more drugs. ${ }^{7}$ Polypharmacy is one of the leading causes of adverse drug reactions (ADRs) in psychiatric patients. ${ }^{8}$ ADR monitoring helps in developing appropriate interventional strategies to manage, prevent and minimize the risk of developing ADRs and thereby reducing the cost of care. ${ }^{2}$

The study of ADRs is the field known as pharmacovigilance. $^{7}$ Pharmacovigilance is the pharmacological science relating to the detection, assessment, understanding and prevention of adverse effect, particularly long term and short term side effects of medicines. ${ }^{9}$ The rate of ADR reporting in India is below $1 \%$, as against the world rate of $5 \% .{ }^{4}$ In India, ADR monitoring is in initial stage and it is highly essential as there is lack of adequate data related to safety of drugs in general and psychotropic agents in particular and there are only few reports available on incidence of ADRs due to psychopharmacological agents. ${ }^{4}$ Therefore, this study will help to evaluate the ADR profile of psychotropic drugs used in the psychiatry outpatient department in the tertiary care teaching hospital.

Aim of the study was to evaluate the nature of ADRs and to estimate the incidence of ADRs, to assess the causality and severity of the documented ADRs and to identify the modes of management of ADRs to psychotropic drugs in the psychiatry out-patient department of a tertiary care hospital.

\section{METHODS}

\section{Study design}

The study was conducted at the psychiatry outpatient department of tertiary care teaching hospital, Tirunelveli medical college in India. This was a prospective observational study and was conducted for 1 month, April 2017. Written informed consent was obtained from all the patients included in the study in their own vernacular language.

\section{Inclusion and exclusion criteria}

Patients of all age groups and both the gender, diagnosed with any psychiatric disorder as per International classification of disease - ICD 10 criteria on psychotropic medications were included in the study. Patients with known substance abuse, patients with mental retardation and patients not accompanied by family care taker were excluded from the study.
Patients enrolled in the psychiatry OPD were screened for ADRs. Patient demographic details, diagnosis, psychotropic drugs prescribed and their adverse drug reaction, any associated disease, any other medication consumed by the patients were recorded.

ADR reporting form was used to record all the essential information regarding the adverse effects like the onset and severity of the ADR experienced by the drug or drugs, the date of starting of the suspected drugs and the date of reporting of the ADR. Age group wise and system wise distribution of ADR's were tabulated and analysed.

WHO-UMC causality assessment system was used to categorise ADRs as certain, probable or possible. Modified Hartwig and Siegel scale was used to categorise the reported ADRs as mild, moderate or severe based on the treatment and requirement of hospitalization for the management of the ADRs. Modes of management in patients with ADR such as discontinuation, reduction in dose or substitution of another drug to the current regimen were tabulated. Data obtained were statistically analysed using descriptive statistics and expressed in percentage.

\section{RESULTS}

A total of 2,727 patients attended the psychiatry OPD in the month of April 2017, out of which 582 patients were diagnosed to have at least one ADR. The incidence of ADRs observed in the psychiatry OPD to psychotropic drug was $21.34 \%$. Among the 582 patients with ADR there was male preponderance of $362(62.19 \%)$ patients as compared to $220(37.80 \%)$ female patients. The mean age of the subjects with ADRs in males were 35.2 years and in females were 32.4years.

The incidence of ADR to psychotropic drugs was highest in age group of $31-40$ years $(8.91 \%)$ followed by $21-30$ years $(5.09 \%$ ) (Table 1). A total of 23 adverse drug reactions were reported from 14 psychotropic drugs.

Table 1: Psychotropic drug induced adverse drug reaction in different age groups.

\begin{tabular}{|lll|}
\hline $\begin{array}{l}\text { Age Group } \\
\text { (years) }\end{array}$ & $\begin{array}{l}\text { Total number } \\
\text { of patients (n) }\end{array}$ & $\begin{array}{c}\text { Patients with } \\
\text { ADR } \mathbf{n}(\%)\end{array}$ \\
\hline $0-10$ & 25 & $4(0.15 \%)$ \\
\hline $11-20$ & 194 & $28(1.03 \%)$ \\
\hline $21-30$ & 737 & $139(5.09 \%)$ \\
\hline $31-40$ & 831 & $243(8.91 \%)$ \\
\hline $41-50$ & 625 & $112(4.11 \%)$ \\
\hline $51-60$ & 213 & $38(1.39 \%)$ \\
\hline $61-70$ & 102 & $18(0.66 \%)$ \\
\hline Total & 2727 & $582(21.34 \%)$ \\
\hline
\end{tabular}

$\mathrm{n}$ is number of patients; 2,727 patients attended the OPD; 582 patients developed atleast one ADR

The most common adverse effect reported was sedation $(3.44 \%)$ followed by weight gain $(3.04 \%)$, extrapyramidal 
symptoms $(2.79 \%)$ nausea and vomiting $(2.09 \%)$. The least common adverse reactions were skin rash $(0.18 \%)$, Parkinson's disease, headache and seizure precipitation $(0.15 \%)$, amenorrhea and restlessness $(0.11 \%)$ (Table 2$)$.

Table 2: Adverse drug reactions induced by psychotropic drug.

\begin{tabular}{|lll|}
\hline Reactions & $\begin{array}{l}\text { Frequency } \\
(\mathbf{n})\end{array}$ & $\begin{array}{l}\text { Percentage } \\
(\boldsymbol{\%})\end{array}$ \\
\hline Sedation & 94 & 3.44 \\
\hline Weight gain & 83 & 3.04 \\
\hline EPS & 76 & 2.79 \\
\hline Nausea and vomiting & 57 & 2.09 \\
\hline Dryness of mouth & 41 & 1.50 \\
\hline Palpitation & 32 & 1.17 \\
\hline Tremor & 30 & 1.10 \\
\hline Hypersalivation & 27 & 0.99 \\
\hline Anorexia & 25 & 0.92 \\
\hline Galactorrhoea & 24 & 0.88 \\
\hline Dizziness & 20 & 0.73 \\
\hline Sexual dysfunction & 15 & 0.55 \\
\hline Insomnia & 9 & 0.33 \\
\hline Hypotension & 7 & 0.26 \\
\hline Diabetes mellitus & 7 & 0.26 \\
\hline Constipation & 6 & 0.22 \\
\hline Gastritis & 6 & 0.22 \\
\hline Skin rash & 5 & 0.18 \\
\hline Parkinson's disease & 4 & 0.15 \\
\hline Headache & 4 & 0.15 \\
\hline Seizure precipitation & 4 & 0.15 \\
\hline Amenorrhea & 3 & 0.11 \\
\hline Restlessness & 3 & 0.11 \\
\hline is & 34 s & \\
\hline
\end{tabular}

$\mathrm{n}$ is number of patients. EPS is extrapyramidal symptoms

The most Common class of drug that produced adverse reactions among the 582 patients were antidepressants $(10.93 \%)$ followed by antipsychotics $(6.86 \%)$ and the least common class of drug that produced adverse drug reaction was antimanic drugs $(0.58 \%)$ (Table 3$)$.

Table 3: Class of psychotropic drugs causing adverse drug reaction.

\begin{tabular}{|lll|}
\hline Psychotropic drugs & $\begin{array}{l}\text { Frequency } \\
(\text { n) }\end{array}$ & $\begin{array}{l}\text { Percentage } \\
(\%)\end{array}$ \\
\hline Antidepressants & 298 & 10.93 \\
\hline Antipsychotics & 187 & 6.86 \\
\hline Sedatives and Hypnotics & 47 & 1.72 \\
\hline Antiepileptics & 34 & 1.25 \\
\hline Antimanicdrugs & 16 & 0.58 \\
\hline
\end{tabular}

$\mathrm{n}$ is number of patients

The most common antidepressant to produce adverse drug reactions were fluoxetine $(3.89 \%)$ followed by sertraline $(3.59 \%)$, escitalopram $(1.28 \%)$, imipramine $(1.21 \%)$. The antipsychotics that produced adverse reactions were olanzapine $(2.90 \%)$ followed by haloperidol $(1.69 \%)$, risperidone (1.25\%), chlorpromazine (0.62\%), trifluperazine $(0.40 \%)$. The sedative and hypnotic that produced adverse reaction was diazepam (1.72\%). Antiepileptic's that produced adverse reactions were carbamazepine $(0.44 \%)$ and sodium valproate $(0.81 \%)$. The antimanic drug that produced adverse reaction was lithium $(0.59 \%)$ (Table 4).

Table 4: Psychotropic drugs causing adverse drug reaction.

\begin{tabular}{|lll|}
\hline Drugs & Frequency (n) & Percentage (\%) \\
\hline Fluoxetine & 106 & 3.89 \\
\hline Sertraline & 98 & 3.59 \\
\hline Olanzapine & 79 & 2.90 \\
\hline Diazepam & 47 & 1.72 \\
\hline Haloperidol & 46 & 1.69 \\
\hline Escitalopram & 35 & 1.28 \\
\hline Risperidone & 34 & 1.25 \\
\hline Imipramine & 33 & 1.21 \\
\hline Amitriptyline & 26 & 0.95 \\
\hline Sodium valproate & 22 & 0.81 \\
\hline Chlorpromazine & 17 & 0.62 \\
\hline Lithium & 16 & 0.59 \\
\hline Carbamazepine & 12 & 0.44 \\
\hline Trifluperazine & 11 & 0.40 \\
\hline
\end{tabular}

$\mathrm{n}$ is number of patients

The most common system associated with adverse reactions were central nervous system $(8.21 \%)$ followed by endocrinal system (4.29\%). The least common system associated with adverse reaction was reproductive system $(0.55 \%)$ followed by dermatology $(0.18 \%)$ (Table 5$)$.

Table 5: System associated with adverse drug reaction to psychotropic drugs.

\begin{tabular}{|lll|}
\hline System & $\begin{array}{l}\text { Frequency } \\
\text { (n) }\end{array}$ & $\begin{array}{l}\text { Percentage } \\
(\%)\end{array}$ \\
\hline Central nervous system & 224 & 8.21 \\
\hline Endocrinal system & 117 & 4.29 \\
\hline Gastrointestinal system & 94 & 3.45 \\
\hline $\begin{array}{l}\text { Autonomic nervous } \\
\text { system }\end{array}$ & 68 & 2.49 \\
\hline Cardio vascular system & 39 & 1.43 \\
\hline Vestibular & 20 & 0.73 \\
\hline Reproductive system & 15 & 0.55 \\
\hline Dermatology & 5 & 0.18 \\
\hline
\end{tabular}
$\mathrm{n}$ is number of patients

Table 6: Causality assessment of adverse drug reactions induced by psychotropic drugs.

\begin{tabular}{|lll|}
\hline Causality & Frequency (n) & Percentage (\%) \\
\hline Probable & 428 & 15.69 \\
\hline Possible & 154 & 5.65 \\
\hline Certain & Nil & Nil \\
\hline
\end{tabular}

$\mathrm{n}$ is number of patients 
The causality assessment of adverse drug reaction induced by psychotropic drugs was probable in 428 (15.69\%) patients, possible in $154(5.65 \%)$ patients and no patient was found to be certain (Table 6).

The severity of adverse reaction induced by psychotropic drugs were mild in severity in 459 (16.83\%) patients, moderate in $119(4.36 \%)$ and severe in $4(0.15 \%)$ patients (Table 7).

\section{Table 7: Severity of adverse drug reaction induced by} psychotropic drugs.

\begin{tabular}{|lll|}
\hline Severity & Frequency (n) & Percentage (\%) \\
\hline Mild & 459 & 16.83 \\
\hline Moderate & 119 & 4.36 \\
\hline Severe & 4 & 0.15 \\
\hline
\end{tabular}

$\mathrm{n}$ is number of patients

The various modes of management of ADRs produced by psychotropic drugs were as follows, about 403(14.78\%) patients with ADRs continued the same medication with reassurance alone, another drug was added to treat the ADR alone with the continuation of existing medication in 112 patients $(4.11 \%)$,the suspected drug was discontinued in 46 patients $(1.68 \%)$ who experienced ADR and was substituted with an alternate drug and decrease in dosage of the suspected drug was done in 21 patients $(0.77 \%)$ who experienced ADR (Table 8).

Table 8: Modes of management of adverse drug reactions to psychotropic drugs.

\begin{tabular}{|lll|}
\hline Treatment & $\begin{array}{l}\text { Number of } \\
\text { ADRs (n) }\end{array}$ & Percentage (\%) \\
\hline $\begin{array}{l}\text { Continued same } \\
\text { treatment }\end{array}$ & 403 & 14.78 \\
\hline $\begin{array}{l}\text { Added another } \\
\text { drug to treat }\end{array}$ & 112 & 4.11 \\
ADR & 46 & 1.68 \\
\hline $\begin{array}{l}\text { Substituted } \\
\text { another drug }\end{array}$ & 21 & 0.77 \\
\hline $\begin{array}{l}\text { Decrease in } \\
\text { dosage }\end{array}$ & & \\
\hline
\end{tabular}

$\mathrm{n}$ is number of patients

\section{DISCUSSION}

The present study has reported the incidence of suspected ADRs to psychotropic drugs in the psychiatry OPD. A knowledge, attitude and practice based study conducted in Norway found that ADRs can be prevented by collecting reliable information about their frequencies and possible risk factors. ${ }^{1}$ In pharmacovigilance, spontaneous reporting is the best and the most common method used and it is also the best one to generate signals on new and rare ADRs. The major drawback of this system is under reporting due to lack of awareness both at the level of healthcare professionals and patients. ${ }^{3}$
In the present study, the mean age of the patients with ADRs among men was 35.2 years and in women was 32.4 years and it is similar to the study conducted by Sengupta et al. $^{3}$ The sex distribution of patients with ADR in this study was $362(62.19 \%)$ males and $220(37.80 \%)$ females. In the present study on an average $62 \%$ of patients attending the psychiatry OPD were males. This is similar to the study conducted by Sengupta et $a .^{3}$ In the present study 2,727 patients were screened in the psychiatry OPD, $582(21.34 \%)$ were having at least one ADR. This is similar to a study conducted by Prajapati et al, which showed that among 2000 patients screened in psychiatry OPD, $429(21.45 \%)$ patients were having at least, one ADR. ${ }^{10}$

The maximum numbers of ADRs reported in this study is in the age group 31-40 year's age group but study conducted by Taruna Sharma et al showed that maximum numbers of ADRs were reported in 20-29 years age group. ${ }^{4}$ In the present study maximum numbers of ADRs were seen with antidepressant drugs similar to the study conducted by Taruna Sharma et al and Shah et al. ${ }^{1,4}$ The most commonly prescribed drugs were selective serotonin reuptake inhibitors like fluoxetine and sertraline, similar to the study conducted by Jisha et al. ${ }^{11}$ A Brazilian study analysed 219 notifications of suspected ADRs of psychotropic drugs and found that antidepressants were the most common group responsible for ADRs followed by antipsychotics. ${ }^{3}$ The next common group to produce ADRs in our study was antipsychotics.

In the present study the most common ADR was sedation and it was observed in 94 patients $(3.44 \%)$ followed by weight gain in 83 patients $(3.04 \%)$. This is similar to the study conducted by Taruna Sharma et al. ${ }^{4}$ Increased sleep has significant disruption of sleep wake cycle due to the side effect of psychotropic drugs. ${ }^{4}$ The most common ADRs produced by antidepressants were gastrointestinal symptoms like nausea and vomiting, loss of appetite and dryness of mouth, similar to the study conducted by Jisha et al. ${ }^{11}$

The most commonly prescribed antipsychotic was olanzapine in 79 patients $(2.90 \%)$ followed by haloperidol in 46 patients $(1.69 \%)$ similar to study conducted by Sengupta et al. ${ }^{3}$ Typical antipsychotic haloperidol was prescribed with limitation of poor efficacy against negative symptoms and unwanted extrapyramidal symptoms. Atypical antipsychotic olanzapine differ from conventional agents in that they have lower risk of extrapyramidal symptoms and significantly reduce both positive and negative symptoms of schizophrenia. ${ }^{1}$ Most common ADRs produced by olanzapine in the present study was weight gain, increased appetite and diabetes mellitus, similar to study conducted by Shah et al, Sengupta et al and Kiran et al. ${ }^{1,3,12}$ Haloperidol produced maximum extrapyramidal symptoms similar to study conducted by Taruna et al. ${ }^{4}$ Extrapyramidal symptoms can impair quality of life, stigmatise patients and lead to poor antipsychotic adherence and relapse. ${ }^{4}$ 
The causality assessment in our study had no certain cases as rechallenge was not attempted by the psychiatrist once a drug was withdrawn. Regarding the severity assessment of psychotropic drugs, $4(0.15 \%)$ patients required intensive medical care as they developed severe hypotension and arrhythmia. No fatal ADRs were documented.

The result of our study gives the interpretation that the majority of ADRs had probable relation in 428 patients (15.69\%) to the psychotropic drug. The severity assessment of the reported ADRs revealed that most of the ADRs were mild in 459 patients $(16.83 \%)$. In this study, $403(14.78 \%)$ did not require modification of treatment or administration of specific antidotes and they continued the same treatment. It is well understood from the study that constant vigil in detecting ADRs and subsequent dose adjustments or substituting with an alternate drugs can make therapy with psychotropic drugs safer and more effective.

\section{Limitations}

There is difficulty in identifying which particular drug produced ADRs as there is utilisation of multiple drugs with overlapping toxicities for the management of various psychiatric illness. The duration of the study was very short and the study subjects were confined to OPD only. Hence further studies involving longer duration could be more beneficial in identifying wide spectrum of ADRs to wide variety of psychotropic medication.

\section{CONCLUSION}

The present study represents the ADR profile that could be expected in the psychiatry OPD. Active intensive monitoring of ADRs to psychotropic drugs in psychiatry OPD can help in early detection of ADRs, prevent serious complications produced by ADRs, thereby promote continuity of care, encourage adherence to therapy, reduction in treatment cost and ensure successful completion of treatment.

\section{ACKNOWLEDGEMENTS}

Authors would like to thank the head of the Department, Psychiatry, professor Dr. Ramanujam and Pharmacology Professor Dr. Ezhil Ramya for guiding me throughout the study.

Funding: No funding sources Conflict of interest: None declared

Ethical approval: The study was approved by the Institutional Ethics Committee

\section{REFERENCES}

1. Shah VM, Mehta DS. A longitudinal study of monitoring adverse drug reaction at psychiatry out- patient department in our tertiary care teaching hospital, Surendranagar. JDDT. 2014;4(1):49-52.

2. Sridhar SB, Al-Thamer SSF, Jabbar R. Monitoring of adverse drug reactions in psychiatry outpatient department of a secondary care hospital of Ras Al Khaimah, UAE. J Basic Clin Pharm. 2016;7(3):80-6.

3. Sengupta G, Bhowmick S, Hazra A, Datta A, Musifikur R. Adverse drug reaction monitoring in psychiatry out-patient department of an Indian teaching hospital. Indian J. Pharmacol. 2011;43(1):369.

4. Sharma T, Vishwakarma K, Dhasmana DC, Gupta R, Kalra J, Sharma U. Adverse drug reaction monitoring in psychiatry outpatient department of a tertiary care teaching hospital. JK Science. 2014;16(4):156-60.

5. Solanke B, Mahatme MS, Dakhale G, Hiware S, Shrivastava M, Waradkar P. Adverse drug reaction profile at psychiatry out-patient department of a tertiary referral centre in Central India. Int J Basic Clin Pharmacol. 2013;2:341-3.

6. Gummadi T, Harave VS, Aiyar LN, Raja Lekshmi SG, Kunnavil R. Adverse drug reaction monitoring in a tertiary care psychiatry setting: a comparative study between inpatients and outpatients. Indian $\mathrm{J}$ Psychol Med. 2017;39(3):306-11.

7. Pahari N, Tripathi SK, Maity T, Gupta BK, Bagchi C, Mondal DK. Evaluation and analysis of adverse drug reactions of second generation antipsychotics in a psychiatry out-patient department. Int J Pharm Sci. 2012;4(5):158-62.

8. Rani FA, Byrne PJ, Murray ML, Carter P, Wong IC. Paediatric atypical antipsychotic monitoring safety (PAMS) study: Pilot study in children and adolescents in secondary and tertiary care settings. Drug Saf. 2009;32:325-33.

9. Tripathi KD. Adverse drug effects. Essentials of medical pharmacology. $7^{\text {th }}$ Edition New Delhi: Jaypee Brothers; 2013:82-83.

10. Prajapati HK, Joshi ND, Trivedi HR, Parmar MC, Jadav SP, Parmar DM. Adverse drug reaction monitoring in psychiatric outpatient department of a tertiary care hospital. Natl J Integr Res Med. 2013;4:102-6.

11. Lucca JM, Madhan R, Gurumurthy P, Dushad R. A prospective observational study to evaluate safety reporting of antidepressants at a tertiary care hospital in India. Indian J. Pharmacol. 2014;46(5):543-6.

12. Piparva KG, Buch JG, Chandrani KV. Analysis of adverse drug reactions of atypical antipsychotic drugs in psychiatry OPD. Indian $\mathbf{J}$ Psychol Med. 2011;33(2):153-7.

Cite this article as: Nalini R. Pharmacovigilance study in psychiatry out-patient department of a tertiary care teaching hospital. Int J Basic Clin Pharmacol 2017;6:2375-9. 